\title{
Size - Productivity Relationship in Pakistan's Agriculture in the Seventies
}

\author{
M. GHAFFAR ChAUDhry, MANZOOR A. Gill \\ and GHULAM MUSTAFA CHAUDHRY*
}

A large majority of the less developed countries, including Pakistan, suffer from low levels of productivity in agriculture. In view of the scarcity of farm land and the limitations of intensive margins of cultivation, the importance of raising these levels may not be underestimated in terms of a more judicious use of labour force, rapid growth of agricultural production and increased availability of funds for industrial development. Productivity gains favouring well-to-do farmers, however, may produce undesirable results such as deterioration of income inequalities, political instability and social unrest, and must be avoided as far as possible. It is in this context that the distribution of productivity gains among various size groups should be taken to be as important as the aggregate growth of farm productivity, if not more.

In spite of the discontinuities at times, aggregate productivity in Pakistan's agriculture has been on the increase since the early Sixties. While the distribution of these gains is a controversial issue, it has implications for the fundamental size productivity relationship. For example, it is a commonly accepted view that the productivity increases of the Sixties were largely concentrated in the hands of the large farmers because of their financial superiority for investing in key agricultural inputs and high-value cash crops and their advantageous position for benefiting from government programmes of input subsidies, price supports and institutional credit [7, p. 706; 8, p. 364; and 19, p. 196]. Arguing on these lines, Berry and Cline have statistically shown, although on the basis of comparisons of inherently incomparable data, that in Pakistan the large farmers have overtaken the traditionally more productive small farmers in productivity [2, pp. 90-125]. Mahmood and Nadeem [11, p. 186] , however, deny the existence of a positive size - productivity relationship on the basis of the 1973 farm data and argue that the smallest and the largest farms have the highest productivity. By contrast, a recent study by one of the authors of this paper concluded that the rate of growth of the productivity of the small farmers

*The authors are, respectively, Chief of Research, Associate Staff Economist and Technical Assistant at the Pakistan Institu te of Development Economics, Islamabad. 
was considerably greater than the corresponding rate for the large farmers throughout the Sixties, with the result that the traditional inverse relationship between farm size and farm productivity remained valid until the early Seventies [3, p. 179] The study also suggested, albeit without citing supportive empirical evidence, that these trends in productivity were likely to continue into most of the Seventies.

The conclusions of the various studies being controversial, the present paper makes an attempt to resolve some of the controversies with the help of fresh empirical evidence from the early Seventies and the early Eighties. The study is organized into four sections. The data sources and methodology are discussed in Section 1. Section 2 presents empirical results. An attempt is made in Section 3 to identify the factors responsible for the more rapid growth of the productivity of small farmers in relation to that of the large ones and the consequent emergence of a more vivid inverse size - productivity relationship with the passage of time. Finally, Section 4 presents the summary and the policy recommendations of this paper.

\section{DATA SOURCES AND METHODOLOGY}

For the data required for this study, we had to rely on two sources of data, viz. IRDP survey of 1973-74 and the PIDE Wheat Market Survey of 1981-82 for several reasons. Firstly, the two surveys cover the whole country. Secondly, they are based on large samples: 1143 farmers covered by PIDE survey, and 53125 farmers by IRDP survey. Thirdly, despite the general scarcity of income accounts data by farm size, both the sources contain farm income data disaggregated by farm size. It may, however, be noted that while the PIDE survey allows disaggregation by individual farms, the IRDP survey data are markaz aggregates for various farm-size groups. This loss of disaggregation in the IRDP survey, though a possible source of biases in data leading to spurious relationships, is unlikely to pose problems because of the almost infinite size of the sample well distributed among all farm-size groups [1, p. A-197]. Needless to add that in this study the above-mentioned two major sources of data are thoroughly supplemented by other sources wherever necessary.

Our methodology involves statistical estimation of various forms of equations, such as linear, log-linear and quadratic. One of the most simple equations is the one that is based on a linear relationship between productivity and farm size and is expressed as follows:

$$
Y=a+b X_{1}
$$

where

$Y=$ productivity per cultivated acre,

$a=$ a constant, and

$b=$ the estimated parameter for the explanatory variable $X_{1}$, the farm size.
For a log-linear relationship between farm size and productivity, the appropriate equation is

\section{$\log Y=a+b \log X_{1}$}

To test the proposition that productivity first falls and then rises after reaching a certain level of farm size, it is desirable to use the quadratic form of equation such as

$$
Y=a+b X_{1}+c X_{1}^{2}
$$

Although these equations relate farm productivity to farm size alone, the list of explanatory variables can be expanded to include any agricultural input. While a study of the productivity changes resulting from the rising use of modern agricultural inputs is important, our surveys lack the necessary data to enable us to accomplish this task statistically. However, our surveys do permit us to study the impacts of cropping intensities and crop yields on farm productivities which we have incorporated in our analysis and statistical estimation of the relevant equations. Since the two surveys which we have used for this study lack the relevant data on the use of critical agricultural inputs by various farm-size groups, we have derived such data from other sources, especially the Agricultural Censuses of 1972 [17] and 1980 [18].

\section{RESULTS AND DISCUSSION}

To explore any size - productivity relationship, we have used in this section two basic approaches to the problem. Firstly, we present absolute levels of productivity in the early Seventies and the early Eighties by discrete farm-size groups and discuss their implications for the fundamental relationship between farm size and productiv ity. Secondly, treating the farm size as a continuous, rather than as a discrete, variable, we supplement and confirm the conclusions of the first approach through regression analysis. Based on the first approach, Table 1 presents average farm productivity data as obtained on various farm sizes in 1973-74 and 1981-82.

Three major conclusions follow from Table 1. Firstly, Pakistan's agriculture is characterized by considerable productivity differenes between various farm-size categories, especially between small farmers and large farmers. As a general rule, small farmers seem to be more productive than the large ones. It is not difficult to see from the table that the productivity of the small farmers exceeded that of the large farmers by about 15 percent in 1973-74 and by 21 percent in 1981-82 Secondly, the rate of growth of farm productivity between 1973-74 and 1981-82 was slightly greater for the small farmers than for the large farmers. This implies that the productivity differences between the two classes of farmers continued to widen over the period under consideration. This then negates the finding of Berry and Cline 
Table 1

Farm Productivity by Farm Size: 1973-74 and 1981-82

Productivity per Cultivated Acre (Rupees)

Farm-Size Categories

$1973-74$

$1981-82$

\begin{tabular}{lll}
\hline Small : up to 12.5 acres & 565.3 & 1870.2 \\
Medium: $12.5-25.0$ acres & 478.9 & 1615.6 \\
Large : above 25.0 acres & 492.3 & 1542.6 \\
\hline
\end{tabular}

Sources: $[14 ; 15 ; 16]$.

[2, pp. 90-125] that in Pakistan the large farmers overtook the small farmers in farm productivity. Thirdly and finally, although there is a clear indication of the existence of an inverse size - productivity relationship for the year 1981-82, the relationship for 1973-74 seems to be of quadratic type as productivity first falls from small farms to medium-sized farms and then rises from medium-sized farms to large farms.

It may be interesting to note that the above conclusions are considerably sharpened if the productivity per acre is defined in terms of the farm area rather than the cultivated area. This is because the land-use intensity (ratio of cultivated area to farm area) is inversely related to farm size $[17 ; 18]$.

The above conclusions, however, may prove to be erroneous because the above analysis treats the farm size as a discrete variable and does not take into account the question of the statistical significance of the results obtained. These conclusions may also be biased as the above analysis assumes linearity of relationship between farm size and productivity. Many of these problems, however, can largely be avoided if we regress productivity per acre on farm-size data, using various functional forms. The results of such an excercise for 1973-74 and 1981-82 are reported in the form of the following six equations along with $t$-values of the estimated coefficients. ${ }^{1}$

$$
\begin{aligned}
& Y=523.264-0.428 X_{1} \quad \ldots \ldots \ldots \\
& \bar{R}^{2}=0.003
\end{aligned}
$$

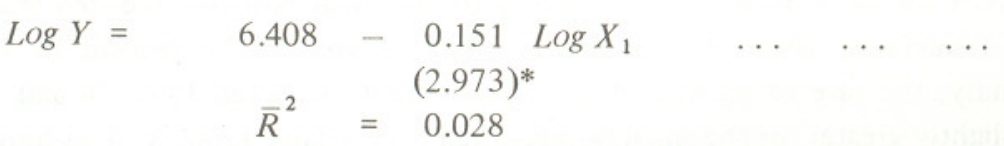

${ }^{1}$ Figures in parentheses refer to $t$-values, and the number of stars represents the percentage of the level of statistical significance of the coefficients: one star for 1 percent; two stars for five percent; and three stars for 10 percent.

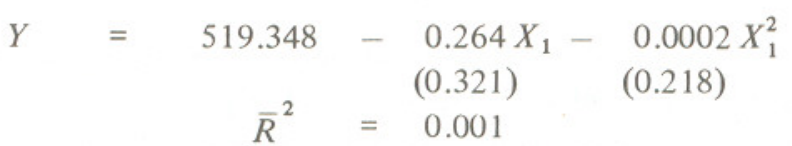

\begin{tabular}{|c|c|c|c|c|c|c|c|}
\hline$Y$ & $=$ & $\begin{array}{r}1823.696 \\
\bar{R}^{2}\end{array}$ & $\begin{array}{l}- \\
=\end{array}$ & $\begin{array}{l}3.113 X_{1} \\
(1.827)^{* *} \\
0.020\end{array}$ & $\cdots$ & $\cdots$ & $\ldots$ \\
\hline $\log Y$ & $=$ & $\begin{array}{c}7.526 \\
\bar{R}^{2}\end{array}$ & $\begin{array}{l}- \\
=\end{array}$ & $\begin{array}{l}0.125 \log X_{1} \\
(3.500)^{*} \\
0.034\end{array}$ & $\ldots$ & $\ldots$ & $\ldots$ \\
\hline$Y$ & - & $\begin{array}{r}1914.682 \\
\bar{R}^{2}\end{array}$ & $\begin{array}{l}- \\
=\end{array}$ & $\begin{array}{l}11.010 X_{1}+ \\
(3.208)^{*} \\
0.011\end{array}$ & $\begin{array}{c}0.022 X_{1}^{2} \\
(2.648)^{*}\end{array}$ & $\cdots$ & $\cdots$ \\
\hline
\end{tabular}

For 1981-82

It is apparent from the above equations that the relationship between farm size and productivity in both $1973-74$ and 1981-82 is neither linear nor quadratic but log-linear. This follows from the higher explanatory power of the log-linear equation as reflected in the values of $\bar{R}^{2}$. Equations (2) and (5) are sufficiently clear to support the contention of inverse relationship between farm size and productivity as the coefficient of farm size in both 1973-74 and 1981-82 proved to be statistically significant at the 1 -percent level of significance. ${ }^{2}$ From a comparison of equation (2) with equation (5) it becomes clear that the explanatory power of the farm size variable has been more pronounced in 1981-82 than in 1973-74.

\section{EXPLAINING THE INVERSE RELATIONSHIP}

Productivity per cultivated acre is basically a function of cropping intensity, crop yields and cropping pattern. The differences in productivity per acre should, therefore, be attributed to the differences in either any or all of these variables among the various farm-size categories. In the specific case of Pakistan, all these variables seem to be of considerable importance. For example, it has been shown in a recent study by Cornelisse and Naqvi $[6$, p. 31] that, contrary to the findings by Salam for the early Seventies [21, p. 324], wheat yields were inversely related to

${ }^{2}$ This, however, is not to argue that the relationship will hold indefinitely but to show that inverse relationship between farm size and productivity in Pakistan still existed in 1981-82. One of the policy implications of this conclusion, as argued in a later section, is the economic feasibility of a redistributive land reform for stepping up agricultural production. 
farm size in Pakistan. Similarly the cropping intensities of the small farmers exceed. ed 122.6 percent and 134.8 percent for 1972 and 1980 respectively in contrast to 99.1 percent and 109.2 percent of those of large farmers for the same two years [17; 18]. The results of our regression analysis seem to confirm the above conclusions as shown by the following two equations:

For 1973-74

$$
\begin{aligned}
\log Y= & 2.320- \\
& 0.251 \log X_{1}+0.815 \log X_{2} \ldots \\
& (1.584) \\
\bar{R}^{2} & =0.345
\end{aligned}
$$

\section{For 1981-82}

$$
\begin{aligned}
\log Y=\quad 1.839- & 0.093 \log X_{1}+1.094 \log X_{2} \ldots \\
& (1.746)^{* * *} \ldots \\
\bar{R}^{2} & =0.292
\end{aligned}
$$

In line with Khan's findings [10, pp. 205-7], the above equations show that cropping intensity, represented here by $X_{2}$, is positively and significantly related to farm productivity. Although a one-percent increase in cropping intensity resulted in only a 0.82 -percent increase in productivity in 1973-74, the same increase in cropping intensity in 1981-82 was responsible for a 1.1-percent increase in productivity. This is to imply that cropping intensities assumed a greater role in 1981-82 than in 1973-74 in explaining productivity changes. It is also clear that the inclusion of cropping intensity as an independent variable did not render the farm size variable statistically non-significant and the inverse relationship still remained intact. ${ }^{3}$ Evidently, then, the crop yields in Pakistan were inversely related to farm size in the Eighties.

Although it was not possible to study the mathematical relationship between farm size and cropping pattern, the data reported in the Agricultural Censuses of 1972 and 1980 are sufficiently clear to show that there were no significant differences between small and large farmers in respect of the allocation of area to cash and non-cash crops $[17 ; 18]$.

Compared with large farmers, small farmers are able to realize higher crop yields, despite their higher cropping intensities, because of a more intensive use of most of the key agricultural inputs discussed below.

There is little doubt that compared with small farmers, the large farmers, because of their financial superiority, are in a better position to invest in costly and

${ }^{3}$ As should be clear from equations (7) and (8), the farm size variable was statistically significant at 20 percent in $1973-74$ and at 10 percent in $1981-82$. indivisible capital inputs like tubewells and tractors. The facts on the ground indica that the ownership of tubewells and tractors is heavily concentrated in the hands the large farmers. For at least three reasons, this heavy concentration does $n$ necessarily mean that the large farmers are capable of achieving such rapid growth productivity as would enable them to catch up with small farmers. Firstly, in spite the concentration of ownership, the numbers of tubewells and tractors per unit land area differ little between small and large farmers [5, pp. 62-63]. Secondl tubewell and tractor services can be easily purchased in the open market and it $h$ been noted that the practice of selling water and the institution of contract-ploug ing make tubewell and tractor services quite divisible despite the concentration ownership [9, p. 49]. Thirdly, small farmers may make up for lack of capital inpu through a massive use of traditional inputs such as human labour, animal power an Persian wheel and achieve productivity increase as fast as the large farmers. Th seems to have been happening in Pakistan.

For example, small farmers, as shown earlier, continued to experience highe levels and growths of cropping intensities than large farmers primarily because th labour and bullock-power inputs of the small farmers were 3.5 and 4.0 times th corresponding inputs of the large farmers in 1972 and 1980 respectively $[17 ; 18$ Similarly, the small farmers' percentage of irrigated area far exceeded that of th large farmers despite the concentration of tubewells in the hands of the latter group According to the census data, the irrigated area of the small farmers was close to 79 . percent in both 1972 and 1980 but the irrigated area of the large farmers fell fron 65.0 percent in 1972 to 63.0 percent in 1980 [17; 18].

Although the leading role of the large farmers in the adoption of High-Yield ing Varieties (HYVs) cannot be denied, there is an overwhelming evidence that th differences in the adoption rates between small and large farmers had largely dis appeared by the early Seventies [3, p. 176]. It may be interesting to note that whil the rate of adoption of the HYVs of wheat for both small and large farmers wa nearly 68.0 percent in 1980 , the small farmers devoted nearly 54.0 percent of thei rice area to the HYVs of rice in contrast to 44.0 percent devoted by large farmer [18].

The experience with chemical fertilizers is not very different from the experi ence with the adoption of the HYVs. There were important and significant differ ences in the rates of fertilizer application of the large and small farmers in the Sixtie [3, p. 176]. These differences, however, narrowed down gradually to insignificant levels in the Seventies (Table 2).

It is clear from Table 2 that for most of the crops the level of fertilizer input by small farmers in 1975-76 and 1977-78 compared very well with that of the large farmers. In the period that followed, however, small farmers began to lag behind the 
Table 2

Rates of Fertilizer Application for Various Crops by Small and Large Farmers: 1976-77 to 1980-81

\begin{tabular}{crcrr}
\hline & \multicolumn{4}{c}{ Nutrient Pounds Applied per Acre } \\
\cline { 2 - 5 } Farm Size/Crops & $1975-76$ & $1977-78$ & $1979-80$ & $1980-81$ \\
\hline A. Small Farmers & 77.5 & 96.5 & 93.5 & 81.5 \\
Cotton & 50.0 & 81.0 & 77.5 & 70.5 \\
Rice & 131.0 & - & 156.0 & 131.5 \\
Sugar-cane & 90.0 & - & 112.0 & 102.0 \\
Maize & 74.5 & 103.5 & 107.5 & 107.0 \\
Wheat & & & & \\
& 83.0 & 85.0 & 114.0 & 95.0 \\
Barmers & 44.0 & 102.0 & 101.0 & 76.0 \\
Cotton & 122.0 & - & 151.0 & 141.0 \\
Rice & 98.0 & - & 77.0 & 74.0 \\
Sugar-cane & 73.0 & 106.0 & 113.0 & 110.0 \\
Maize & & & & \\
Wheat & & & & \\
& & & & \\
\end{tabular}

Sources: $[12$, pp. $67-70 ; 13$, p. 55$]$,

large farmers in the application of chemical fertilizer, especially in 1980-81. The underlying reason perhaps lies in the adjustment process necessitated by the rapid increases of fertilizer prices in 1980-81 and the poor financial position of many of the small farmers. By contrast, the large farmers appeared to be in a better position for adjusting themsleves to the price-increase shock because of their financial superiority.

It may, however, be inferred that even the differences between small and large farmers with regard to fertilizer input in 1980-81 were not all that significant and could be considerably reduced or eliminated through a higher manurial input on small farms. The observation has been made that, on an average, small farmers use twice as much farmyard manure per acre as is used by large farmers [4, p. 248] . With a normal four-ton dose, the use of farmyard manure on small farms exceeds by two tons the amount used by the large farmers. Given the chemical composition of farmyard manure, the additional two-ton application on small farms means additional input of 24 nutrient pounds of nitrogen, 6 pounds of phosphorus and 18 pounds of potassium. Thus, although the small farmers may have used less fertilizer than large farmers in 1980-81, the higher manurial input would prove to be instrumental in enabling the small farmers to secure a higher and better soil-nutrient balance than is obtained by large farmers [3, p. 176] .

\section{CONCLUSIONS AND POLICY IMPLICATIONS}

The purpose of the present investigation has been to study the size productivity relationship in Pakistan as it was in the Seventies in the wake of the Green Revolution. The most important conclusion of the study is that the traditional inverse relationship between farm size and productivity still existed in Pakistan, precluding the possibility of a positive relationship. In fact, our analysis clearly shows that the rate of growth of productivity in the Seventies was somewhat more pronounced in the case of small farmers than in that of the large farmers. The reasons why the traditional inverse relationship remains intact are higher labour input, more intensive land use, greater manurial application, high rates of adoption of HYVs and greater irrigated area of the small farmers in relation to the large ones. A number of general and specific policy implications follow from the analysis of this paper, which are as follows.

Firstly, it should be clear from the analysis of this paper that in Pakistan the Green Revolution technology has basically been scale-neutral in its effects on variou classes of farmers. Although tractors and tubewells may be physically indivisible, the practice of selling tubewell water and the institution of contract-ploughing make them quite divisible in terms of flow of their services. It is in view of this scale-neutrality as well as the output contributions of the Green Revolution technologies that the government must increase its emphasis on propagating the cause of these technologies.

Secondly, although the Green Revolution technologies have inherently been scale-neutral, the unequal distribution of gains between small and large farmers, which has been emphasized by some critics of the Green Revolution, has by and large not been the result of inappropriate technology. It has been argued that the unequal distribution has in the main been the outcome of the introduction of appropriate technologies into social, physical and political environments that have been biased against the small producers [20, p. 242]. Given the high levels of productivity of small farmers, it is difficult to underestimate the economic importance of a redistributive land reforms programme to a rapid growth of agricultural output and the changing of the environment in favour of the small farmers.

Thirdly and finally, the propagation of the Green Revolution technologies and their effects on various classes of farmers depend critically on the prevalent price policy in respect of agricultural commodities and key agricultural inputs. An adequate supply of cheap agricultural inputs such as diesel oil, electricity, fertilizers and irrigation water would be potentially suited to the needs of the small farmers 
with widespread implications for the rapid growth of agricultural output. By contrast, rising prices of key agricultural inputs with rising prices of agricultural com modities are likely to benefit the large farmers more than the small farmers. This is because the small farmers are financially poor and market little, if any, produce in contrast to the significant marketed surplus of the financially powerful large farmers.

\section{REFERENCES}

1. Barbier, Pol. "Inverse Relationship between Farm Size and Land Productivity; A Product of Science or Imagination?" Economic and Political Weekly. Vol 19, Nos. 51-52. December 22-29, 1984. pp. A-189 - A-204.

2. Berry, R. A., and R. W. Cline. "Farm Size, Factor Productivity and Technical Change in Developing Countries". June 1976. (Mimeographed)

3. Chaudhry, M. Ghaffar. "Green Revolution and Redistribution of Rural Incomes: Pakistan's Experience”. Pakistan Development Review. Vol. XXI, No. 3. Autumn 1982. pp. 173-205.

4. Chaudhry, M. Ghaffar. "Rural Income Distribution in Pakistan in the Green Revolution Perspective". Pakistan Development Review. Vol. XII, No. 3 , Autumn 1973.

5. Chaudhry, M. Ghaffar. "The Green Revolution and Income Inequality: Some Empirical Evidence from Rural Pakistan: 1960-1975”. Ph. D. Dissertation, University of Wisconsin, Madison, Wis. (USA). 1980. (Unpublished)

6. Cornelisse, Peter A., and Syed Nawab Haider Naqvi. The Anatomy of the Wheat Market in Pakistan. Rotterdam: Erasmus University/Islamabad: Pakistan Institute of Development Economics. October 1984.

7. Falcon, W. P. "The Green Revolution: Second Generation Problems". American Journal of Agricultural Economics. Vol. 52, No. 5. December 1970.

8. Gotsch, Carl H. "The Green Revolution and Future Developments of Pakistan's Agriculture”. In Robert D. Stenvens et al. (eds.), Rural Development in Bangladesh and Pakistan. Honolulu: The University Press of Hawaii. 1976.

9. Johnston, B. F., and Peter Kilby. Agriculture and Structural Transformation: Economic Strategies in Late-Developing Countries. New York: Oxford University Press. 1975.

10. Khan, M. H. Underdevelopment and Agrarian Structure in Pakistan. Lahore: Vanguard Publications Ltd. 1981.

11. Mahmood, M., and Nadeem-ul-Haq. "Farm Size and Productivity Revisited". Pakistan Development Review. Vol. XX, No. 2. Summer 1981. pp. 151-190.

12. National Fertilizer Corporation of Pakistan Ltd. A Study on Differential Impact of Fertilizer Price Increase on Its Use in Pakistan: Fertilizer Use Pattern in Pakistan Kharif 1980. Islamabad. (NFC-NDFC-World Bank Market Research Project). 1981.
13. National Fertilizer Corporation of Pakistan Ltd. A Study on Differenti Impact of Fertilizer Price Increase on Its Use in Pakistan: Fertilizer U. Pattern in Pakistan Rabi 1980-81. Islamabad. (NFC-NDFC-World Bar Market Research Project). 1981.

14. Pakistan Institute of Development Economics. Statistical Report on th Benchmark Survey of Integrated Rural Development Programme Markazes Pakistan. Vol. 1. Punjab and N.W.F.P. Islamabad. October 1976.

15. Pakistan Institute of Development Economics. Statistical Report on th Benchmark Survey of Integrated Rural Development Programme Markazes Pakistan. Vol. 2. Sind, Baluchistan and Azad Kashmir. Islamabad. Octobe 1976.

16. Pakistan Institute of Development Economics. Data Files on the Weat Marke Survey, 1981-82. (Unpublished)

17. Pakistan. Ministry of Food and Agriculture. Agricultural Census Organizatior Pakistan Census of Agriculture 1972: All Pakistan Report. Vol. 1. Lahor 1975.

18. Pakistan. Statistics Division. Agricultural Census Organization. Pakista Census of Agriculture 1980: All Pakistan Report. Vol. 1. Lahore. 1983.

19. Pearse, Andrew. "Technology and Peasant Production: Reflections on Globa Study”. In Howard Newby (ed.), International Perspective in Rural Sociolo gy. Chichester, New York, Brisbane and Toronto: John Wiley and Sons 1976.

20. Ruttan, Vernon W. "Perspective on Agrarian Reform and Rural Develop ment”. Quarterly Journal of International Agriculture. Vol. 21, No. 3. July September 1982.

21. Salam, Abdul. "Factor Inputs Use and Farm Productivity on Different Farn Categories in the Punjab". Pakistan Development Review. Vol. XVII, No. 3 Autumn 1978. pp. 316-332. 


\section{Comments on}

"Size - Productivity Relationship in Pakistan's Agriculture in the Seventies"

That the relationships between economic variables hardly seem to change with time and space has been amply demonstrated by M. G. Chaudhry and his co-authors. Using data from IRDP (1973-74) and PIDE (1981-82) surveys, they have been able to conclude that the traditional inverse relationship between farm size and productivity still existed in Pakistan and that the rate of growth of productivity in the Seventies was somewhat more pronounced in the case of small farms than in that of the large farms.

We may notice that the theory of returns to scale is concerned with the relationship between the firm's level of output and its long-run average costs when all factors of production are varied in the same proportion. But the scale theory seems to have limited relevance to agriculture in developing countries because of factor rigidities and indivisibilities, even in the long run. In the short run, too, one cannot lose sight of the fact that there is differential access to factors of production (say, in terms of time and space).

Intuitively, if the real price of land declines with increasing farm size, whereas the price of labour increases, the land-labour ratio will tend to vary directly with farm size. That is, ceteris paribus, labour will be used more intensively on small farms, and at these farms output per unit of land area is closely and directly related to labour input. Thus, the productivity of land is largely a reflection of the degree of labour intensity. Consequently, output per acre will tend to be inversely related to farm size. If land is more scarce than labour, as is the case in Pakistan, this argument can easily be carried further to an implication that small farms may utilize resources more efficiently than large farms.

To verify the inverse relationship once more, the authors have estimated linear, quadratic and $\log$-linear equations. In doing so, they have misconceived productivity. Productivity has a physical connotation and is defined as "output per unit of input". Preferably, they should have called their dependent variable as "output per acre". Incidentally, it is not clear if the variable is in gross terms or net terms.

It is unknown as to how many and which crops compose the output per acre (Table 1). If it is an aggregate measure, which seems to be the case, the danger of estimating the equation from a blue-print based on aggregate data is obvious. The inverse relationship can hardly be established for all crops especially in an agriculture which is well on its transitional path.
The authors know that, in agriculture, each enterprise is in some sense unique. Farms differ in their physical characteristics and, above all, farmers differ in their capacity for managerial and manual farm work. Each individual is uniquelly constrained by his own limitations and those of his farm in improving his production through learning by experience. Thus, in analysing farm efficiency, there is need to adopt a disaggregated approach which is not premised on the implicit assumption that all farms are capable of being operated at the same absolute level of technical efficiency or that all farms are capable of reaching the same absolute standard of efficiency.

Viewed in a dynamic perspective, a superior performance of small farms will be observed as long as we have surplus labour. This superiority is expected to disappear as labour becomes scarce and its opportunity cost rises. More importantly, there are a priori reasons for doubting whether this superiority can be sustained in the face of accelerated agricultural transition in Pakistan. In the near future, commercial producers, large in size, are expected to contribute more output per acre. I am referring to commercial producers of maize, tobacco, potato and cotton in different progressive parts of Pakistan.

The observed relationship between farm size and output per acre is based on the assumption of constant quality of land. One wonders if this assumption was tenable in the case of the data used in the study. Across the two samples, the land quality is sure to have varied markedly.

The authors have related higher output per acre of small farms with cropping intensity. This relationship does not seem to offer any hints with respect to the in troduction and development of crops which would enhance the intensity. From the points of view of improved farm management and extension service, the inclusion of this information would have been very useful.

The regression results seem to be rather tenuous. Using a two-tailed test $(B=0)$, the size coefficient has been said to be significantly different from zero at $P \leqslant 0.10$. This, I think, is a miscalculation as the calculated $t$ is less than the one in the $t$-table. This would imply no relationship between the variables and their plot will give a straight line. How successfully the regression has explained the variation in the dependent variable is obvious and hardly needs comments.

In the policy section of their paper, the authors, depending on a rather inconclusive evidence, have alluded to the possibility of another land reforms. Is this evidence sufficient for such a major institutional reform? We know that a number of factors, e.g. physical, institutional and managerial, if not political, go into the analy sis required for such a proposal.

Acting Member,

Social Sciences Division,

Mian M. Aslam

Pakistan Agricultural Research Council, Islamabad 